\title{
A PRÁTICA DE ENFERMAGEM: UMA REFLEXÃO À LUZ DA TEORIA KANTIANA E DO CÓDIGO DE ÉTICA*
}

Anajás da Silva Cardoso ${ }^{1}$, Nathalia Costa Gonzaga ${ }^{1}$, Carla Campos Muniz Medeiros ${ }^{2}$

RESUMO: Trata-se de um estudo qualitativo reflexivo baseado em uma história de vida descrita no livro Re(socialização) da pessoa com deficiência adquirida: o processo, os personagens e as máscaras, o qual trata do processo de reabilitação da pessoa com lesão medular. Neste estudo buscou-se refletir sobre a atuação da equipe de enfermagem ao longo dessa (re)construção social e pessoal à luz da Teoria Kantiana e do Código de Ética Profissional de Enfermagem brasileiro. O processo de reação adaptativa à nova situação da pessoa, como lesada medular, permite refletir a necessidade de melhor qualificação e humanização da assistência prestada por profissionais de saúde que lidam com tal clientela, especialmente a equipe de enfermagem devido às ações de cuidado oferecido e ao vínculo em tempo integral, tornando-os mais propensos a cometer iatrogenias.

PALAVRAS-CHAVE: Ética em enfermagem; Reabilitação; Filosofia em enfermagem.

\section{THE PRACTICE OF NURSING: A REFLECTION IN THE LIGHT OF KANTIAN THEORY AND THE CODE OF ETHICS}

\begin{abstract}
A qualitative, reflexive study based on a life story described in the book Re(socialization) of the person with an acquired handicap: the process, the people and the masks, which deals with the rehabilitation process of people with medullar lesions. This study seeks to reflect on the performance of a nursing team throughout this personal and social (re)construction in the light of Kantian Theory and the Brazilian Code of Professional Ethics in Nursing. The process of adaptive reaction to the person's new situation, i.e. as a person with a medullar lesion, permits reflection on the necessity for better qualification and humanization of the care provided by the healthcare professionals who work with this patient group, especially the nursing team, due to the careactions given and to the full-time nature of the nursing contact, which makes them more likely to commit harmful errors.
\end{abstract}

KEYWORDS: Nursing ethics; Rehabilitation; Philosophy in nursing.

\section{LA PRÁCTICA DE ENFERMERÍA: UNA REFLEXIÓN A LA LUZ DE LA TEORÍA KANTIANA Y DEL CÓDIGO DE ÉTICA}

RESUMEN: Este es un estudio cualitativo reflexivo embasado en una historia de vida descripta en el libro Re(socialização) da pessoa com deficiência adquirida: o processo, os personagens e as máscaras, lo cual habla del proceso de reabilitación de la persona con lesión medular. En este estudio se buscó reflexionar acerca de la actuación del equipo de enfermería en el proceso de esa (re)construcción social y personal a la luz de la Teoría Kantiana y del Código de Ética Profesional de Enfermería brasileño. El proceso de reacción adaptativa a la nueva situación de la persona, como lesado medular, permite reflexionar acerca de la necesidad de más cualificación y humanización de la asistencia prestada por los profesionales de salud que trabajan con esta clientela, especialmente el equipo de enfermería a causa de las acciones en el cuidado ofrecido y al vínculo en tiempo integral, tornándolos más propensos a cometer iatrogenias.

PALABRAS-CLAVE: Ética en enfermería; Reabilitación; Filosofía en enfermería.

\footnotetext{
*Trabalho desenvolvido na disciplina de Bioética, do Programa de Pós-Graduação em Saúde Pública da Universidade Estadual da Paraíba - UEPB, em 2011.

${ }^{1}$ Enfermeira. Mestranda pelo Programa de Pós-Graduação em Saúde Pública da UEPB.

${ }^{2}$ Médica. Doutora em Saúde da Criança e do Adolescente. Professora do Programa de Pós-Graduação em Saúde Pública da UEPB.
} 


\section{INTRODUÇÃO}

A reabilitação é um processo dinâmico, orientado para a saúde, que auxilia um indivíduo que está enfermo ou incapacitado a atingir seu maior nível possível de desempenho físico, mental, espiritual, social e econômico $^{(1)}$. Nesse cenário, o enfermeiro, por sua formação e atuação profissional, desenvolve papeis nos âmbitos educativo, gerencial, na coordenação e implementação da assistência de enfermagem ao binômio paciente e família e à comunidade, tornando-se elemento essencial no cuidar dessa clientela.

O processo de reabilitação descrito na biografia contida na obra Re (socialização) da pessoa com deficiência adquirida. O processo, os personagens e as máscaras ${ }^{(2)}$ é permeado por situações em que a equipe de enfermagem surge de forma dicotômica. Em determinados momentos, as responsabilidades próprias da profissão, preconizados pelo Código de Ética dos profissionais de Enfermagem ${ }^{(3)}$.

Como assegurar ao cliente uma assistência de enfermagem livre de danos decorrentes de imperícia, negligência ou imprudência (Cap I, Seção II, art.21), são transferidas para o acompanhante. Enquanto que, em outras vezes, reconhece seus deveres e atua de forma a garantir a continuidade da assistência de enfermagem (Cap I, Seção I, art.16), prestando adequadas informações ao cliente e à família a respeito da assistência de enfermagem, possíveis benefícios, riscos e consequências que possam ocorrer (Cap I, Seção I, art.17).

Observa-se, entretanto, que as situações mais frequentes associadas à assistência percebidas em ambiente hospitalar, referem-se à iatrogenia, expressa como:

Falha técnica, falha de conduta e na conceituação das infrações ético-legais dessas falhas. Falhas técnicas seriam aquelas relacionadas a erros técnicos ou procedimentais, e as de conduta seriam falhas na atitude, no comportamento, na abordagem interpessoal ou interprofissional. A ocorrência ética consiste em algum tipo de falha cometida pelo profissional de enfermagem, que resulta em prejuízo ao cliente ${ }^{(4: 2)}$.

Iatrogenia abrange, portanto, os danos materiais (uso de medicamentos, cirurgias desnecessárias, mutilações) e psicológicos (psicoiatrogenia - o comportamento, as atitudes, a palavra), causados ao paciente pela equipe de saúde ${ }^{(5)}$. Diante dessa problemática, este estudo teve por objetivo refletir a atuação da equipe de enfermagem ao longo dessa (re) construção social e pessoal à luz da Teoria Kantiana e do Código de Ética
Profissional aprovado pela resolução do Conselho Federal de Enfermagem n. 311/2007(3).

\section{APRESENTANDO O CONTEXTO}

A obra $^{(2)}$ sob reflexão tem uma abordagem qualitativa, do tipo história de vida. Nele, a autora, uma enfermeira, relata fatos de sua infância, adolescência e a vida adulta. É apresentado o processo de escolha da profissão e a dedicação pela qual a exercia, aprofundando-se na docência, além dos aspectos de âmbito pessoal e familiar.

Ao passo que acompanhamos a biografia, conhecemos o motivo pela qual a tornou uma pessoa com deficiência física - um acidente automobilístico quando acompanhada do esposo e do filho. A partir de então, surgem as reflexões de uma enfermeira-cliente acerca do cuidado da equipe de saúde no ambiente hospitalar e do desacreditar dos profissionais, da vivência de uma pessoa com limitações físicas e da determinação para atingir a independência funcional nas tarefas de locomoção, utilizando o vocábulo Fênix, referido na mitologia grega como o pássaro que ressurge das cinzas.

\section{A HISTÓRIA DE VIDA DE UM ENFERMEIRO À LUZ DO CÓDIGO DE ÉTICA}

O exercício da Enfermagem, sob a ótica de assistência integral, garante ao o ser humano ser visto com suas potencialidades, sucessos, fracassos, sentimentos, expectativas, e não apenas que a doença ou o agravo que o acometa seja o problema a ser solucionado. Nesse aspecto, o profissional de enfermagem quando não se aproxima daqueles que estão sob seus cuidados ou, quando o faz de maneira tecnicista, não exerce a profissão segundo os preceitos éticos. Embora seja reconhecido que parcela desta culpa advenha da precariedade dos serviços de saúde no Brasil, impossibilitando uma assistência de qualidade, tal qual prevista no Código de Ética.

Na biografia, nota-se o distanciamento de muitas enfermeiras para com a autora, limitando-se a exercer a "burocracia do cuidado", e desapropriando-se do cuidado propriamente dito, por conseguinte, não estabelece um diálogo com ela e familiares numa relação propícia para prestar adequadas informações a respeito dos direitos, riscos, benefícios e intercorrências acerca da assistência de enfermagem e realizar ações que garantam o direito da pessoa, ou de seu representante legal, de tomar decisões sobre sua saúde, tratamento, conforto e bem-estar, de acordo com o Capítulo I, Seção 
I, artigos 17 e 18 do Código de Ética dos profissionais de Enfermagem ${ }^{(3)}$. Vale ressaltar que esta não era uma característica de todas as enfermeiras, visto que outras mantinham uma relação de diálogo com a autora, discutindo assuntos diversos e propiciando oportunidades para ela decidir sobre seu bem-estar.

O conhecimento do cliente acerca do seu tratamento perpassa os medicamentos administrados. Dessa forma, o profissional de enfermagem, de acordo com o Capítulo I, seção I, artigo 3 do Código de Ética, é proibido administrar medicamentos sem conhecer a ação da droga e sem certificar-se da possibilidade dos riscos $^{(3)}$, reduzindo as iatrogenias. No entanto, muitos profissionais desconhecem a ação dos fármacos ou, quando o conhecem, não se preocupam em informar aos seus pacientes. Assim, esse aspecto também foi um motivo de descontentamento da autora para com a equipe, já que ela constantemente questionava sobre os fármacos administrados, o que ocasionou irritação de membros da equipe de enfermagem que, posteriormente, passaram a informá-la de forma fria e pouco colaborativa.

As críticas apontadas perpassam a prática da Enfermagem, porém é observado que as exigências do mercado de trabalho e da administração hospitalar perpetuam o paradigma do enfermeiro burocrata com uma carga horária exaustiva, dificultando o seu processo de trabalho.

\section{CONTRIBUIÇÃO DAS BASES FILOSÓFICAS KANTIANAS PARA A ENFERMAGEM}

Seguir ou não os preceitos do Código de Ética Profissional é uma abordagem ética que retoma um conceito fundamental para a construção de qualquer documento norteador de práticas, o de responsabilidade.

Responsabilidade é um genuíno conceito moderno, porém seu significado firma-se no âmbito de sociedades seculares, funcionais e diferenciadas. Responsabilizarse por algo significa, originariamente, responder em juízo por seus atos, defendendo e/ou justificando comportamentos oficialmente questionados ${ }^{(6)}$.

Quando o enfermeiro transfere ações de sua incumbência para o acompanhante, ou quando não pratica a assistência da forma correta, ele infringe não só o Código de Ética, mas também seu plano de fundo ou a moral que lhe fundamenta. Dessa forma, o paradoxo da responsabilidade, que envolve todo Código de Ética, em sociedades com padrões operacionais altamente diversificados, não consiste em tomar decisões sob condições incertas, mas em decidir com base em certezas aparentes. Vale dizer, quanto menos o agente social sabe o que ignora, tanto mais tende a avaliar seu saber seletivo como conhecimento sólido e confiável ${ }^{(6)}$.

Além da responsabilidade, a autonomia também representa um conceito que permeia o Código de Ética profissional da enfermagem e, nesse campo, a Teoria Kantiana se destaca, pois são suas reflexões que a embasam.

Deste modo,

a autonomia surge como uma vontade de cuidar de si, sendo que essa vontade tem fundamento na liberdade do sujeito e, para Kant, o fato de a razão ser destacada faz com que a autonomia, associada à moralidade, esteja centrada na subjetividade, sendo assim a vontade está relacionada com uma razão prática, com um dever, imperando a liberdade da vontade sobre o imperativo do dever ou da tarefa ${ }^{(7: 1082)}$.

A ação autônoma é aquela que se guia pela própria lei da razão prática, e ação heterônoma é aquela que se guia por algo que é externo ou contrário à lei da razão prática $^{(8)}$. Razão prática é prática por si mesma, ou seja, ela dá à lei que alicerça a moralidade, a razão fornece as leis práticas que guiam a vontade. Leis práticas são princípios práticos objetivos, regras válidas para todo ser racional. Admitindo-se que a razão pura possa encerrar, em si, um fundamento prático suficiente para a determinação da vontade, então há leis práticas, mas se não se admite o mesmo. Então, todos os princípios práticos serão meras máximas ${ }^{(8)}$.

Partindo desse pressuposto, impressões ou conceitos pré-formados não são leis práticas, não há unidade nem incondicionalidade do agir, assim, não garante a autonomia. Uma moral que se determina por causas empíricas, cai no egoísmo. Por isso, não compete à equipe de enfermagem decidir se uma cliente deve passar ou não batom, como situação vivenciada pela autora da obra ${ }^{(2)}$, simplesmente por causas empirícas, visto que a autonomia é resultante de atitudes com fundamento racional. Sempre que atitudes são adotadas, balizadas em causas empíricas ou sem base científica, tende-se a cometer iatrogenia e um contexto permeado pela possibilidade, sempre latente, de falhar, tanto no procedimento como na conduta. Torna-se evidente a obrigação de corrigir essa falha, não tanto ou não apenas no conhecimento, não tanto ou não apenas na lei, mas na prática de si mesmo ${ }^{(4)}$.

A Enfermagem perdeu, ao longo da história, seu caráter empírico para transformar-se em ciência apli- 
cada, permitindo, assim uma avaliação racional do erro e da culpa profissional. Na tentativa de corrigir tais falhas, a detecção e prevenção dos erros são as principais metas para qualquer instituição. O erro que se procura combater e punir é aquele decorrente da acomodação, do despreparo técnico, da negligência, da imprudência ou imperícia inadmissível e da distração que resulta em morte ou defeito irremediável, comprometimento de órgão ou sentido. É importante lembrar que cuidados, zelo e eficiência são requisitos indispensáveis em qualquer atividade profissional ${ }^{(9)}$.

Para prevenir que a subjetividade individual, compreendida como o espaço íntimo do indivíduo com o qual ele se relaciona com o mundo social ${ }^{(10)}$, interfira nas ações, especialmente no campo da saúde, foi necessário criar normas apoiadas em princípios de virtude, para o benefício geral. As relações de valor que existem entre o ideal moral traçado e os diversos campos da conduta humana podem ser reunidas em um instrumento regulador. Assim, o Código de Ética é uma espécie de contrato de classe por meio dos quais órgãos de fiscalização do exercício da profissão passam a controlar a execução de tal peça magna, tendo como base as virtudes que devem ser exigíveis e respeitadas no exercício da profissão, e abrangendo o relacionamento com usuários, colegas de profissão, classe e sociedade.

Nesse sentido, é relevante a existência de uma ordem para eliminar conflitos e, especialmente, evitar que se macule o bom nome e o conceito social de um grupo profissional.

Finalmente, a Teoria Kantiana se revela ainda mais como norteadora da prática profissional da enfermagem ao afirmar que cada indivíduo deve ser tratado como um fim em si mesmo, e não como um meio para a satisfação de interesses de terceiros ${ }^{(8)}$.

\section{CONSIDERAÇÕES FINAIS}

Conhecer e aplicar o Código de Ética, compreendendo as teorias filosóficas que o fundamentam, é essencial para uma prática de enfermagem livre de danos. Dar atenção, dispor de momentos para escutar as dúvidas, as ansiedades, as angústias dos clientes, é uma pequena parcela do agir ético. Embora pequeno, parece ser um grande passo para a transformação de uma prática que visa a um cuidar personalizado, valorizando o desenvolvimento das competências profissionais e a qualidade dos cuidados.

Sabe-se que a formação ética precisa de um am- biente sadio, com condutas espelhadas em práticas do bem, considerada a vivência com qualidade de vida, sem produzir malefícios a si, nem a seus semelhantes. Todavia, esta condição nem sempre ocorre, em virtude do desleixo dos poderes com má qualidade de ideias e de estrutura, tendo, o indivíduo que deseja conservar seus valores e suas origens éticas que se proteger contra situações de prenúncio.

Em uma sociedade pluralista, como a do mundo atual, os dilemas que permeiam as ações dos profissionais de saúde, entre eles os de Enfermagem, estão presentes no dia-a-dia do cuidar e, em sua maioria, de difícil solução. Portanto, as bases éticas devem ser sempre consideradas: o respeito à dignidade humana, o cumprimento dos princípios de equidade e de não maleficência e, quando as decisões exigirem critérios de seleção, esses devem ser válidos pelos profissionais e pela sociedade.

\section{REFERÊNCIAS}

1. Leite VBE, Faro ACM. O cuidar do enfermeiro especialista em reabilitação físico-motora. Rev. esc. enferm. USP. 2005;39(1):92-6.

2. Franca ISX. A história de uma fênix. In: Re (socialização) da pessoa com deficiência adquirida: o processo, os personagens e as máscaras. João Pessoa: Ed. Ideia; 2000. p.31-89.

3. Conselho Federal de Enfermagem. Resolução n. 311, de 8 de fevereiro de 2007. Dispõe sobre a reformulação do código de ética dos profissionais de enfermagem. [Internet] $17 \mathrm{fev}$ 2007. [acesso em 25 set 2011]. Disponível em: http://site.portalcofen.gov.br/node/4345.

4. Vargas MAO, Ramos FRS. Iatrogenias nas unidades de terapia intensiva: dramaticidade dos problemas bio/ éticos contemporâneos. Rev. latino-am. enfermagem. 2010;18(5):1-9.

5. Padilha KG. Considerações sobre as ocorrências iatrogênicas na assistência à saúde: dificuldades inerentes ao estudo do tema. Rev. esc. enferm. USP. 2001;35(3):287-90.

6. Heck JN. Bioética: contexto histórico, desafios e responsabilidade. Ethica. 2005;4(2):123-39.

7. Souza WS. A saúde pelo avesso. Cienc. saude colet. 2004;9(4):1082-83. 
8. Figueiredo VB. Kant e a crítica da razão pura. Rio de Janeiro: Jorge Zahar Editor; 2005.

9. Sobrinho VG. Carvalho EC. Uma visão jurídica do exercício profissional da equipe de enfermagem. Rev. enferm. UERJ. 2004;12:102-8.

10. Mayo, G. O iluminismo frente ao romantismo no marco da subjetividade moderna. Acesso em 27 set 2011. Disponível: http://www.ub.edu/histofilosofia/gmayos/ PDF/IluminismoFrenteRomantPort.pdf. 